\title{
A New Hybrid Converter Design Using Combined SEPIC-CUK Converters
}

\author{
P. Tamilarasan, Dipanjan Paul, Sagnik Sanjoy Dasgupta, Shubham Sahu, K. Saravanan
}

\begin{abstract}
An improved model of DC-DC converter is proposed in this paper, in light of the blend of the SEPIC and Cuk converters. The said converter is required to work on two shifted sources; a sun powered PV cell and a battery. Despite the fact that each source is to be fit for providing capacity to the circuit, both the sources can give control together if the PV cell doesn't get satisfactory daylight. The Cuk and SEPIC converters are associated with a solitary stage inverter, which gives us our single stage AC yield. For a contribution of $5 W$, the normal yield is assessed to be $3 W$.
\end{abstract}

Index Terms: - Conversion of power (DC-DC), MPPT (Maximum Power Point Tracking), Conversion of power $(D C-A C)$, generation of solar power.

\section{INTRODUCTION}

The job of electrical vitality in our lives is monstrous. Its appropriate use and usage has been instrumental in deciding the way of life of us individuals. This has prompted a regularly developing increment in the interest for power, which is for the most part gotten from petroleum products like coal, oil, flammable gas and so on.

Thinking about clear insufficiencies, the primary drawback of these sources is finishing off with nature, causing extreme ecological contamination and its utilization likewise crosses its limits, and is relied upon to finish in the following couple of decades. Consequently, sustainable power sources are viewed as an elective vitality source to satisfy the need for burden.

At present, imaginative measures and research for creating power is centered around sustainable wellsprings of vitality in light of them being eco-accommodating, bounteous and boundless. In any case, their wild nature and capriciousness are many downsides that should be tended to. This makes it hard to create sufficient measure of capacity to cook the

requesting loads. Additionally, as the power created has a great deal of varieties in voltage and recurrence, the mix of at

Revised Version Manuscript Received on 10, September 2019.

Dr. P. Tamilarasan, (Dept. of EFL), Assistant Professor, Department of Electrical and Electronics Engineering, SRM Institute of Science and Technology, Chennai, Tamil Nadu, India.(Email: tamilarasan.p@ktr.srmuniv.ac.in)

Dipanjan Paul, UG Students, Department of Electrical and Electronics Engineering, SRM Institute of Science and Technology, Chennai, Tamil Nadu, India.(Email: dipanjan96paul@gmail.com)

Sagnik Sanjoy Dasgupta, UG Students, Department of Electrical and Electronics Engineering, SRM Institute of Science and Technology, Chennai, Tamil Nadu, India.(Email: sagnik.dasgupta97@gmail.com)

Shubham Sahu, UG Students, Department of Electrical and Electronics Engineering, SRM Institute of Science and Technology, Chennai, Tamil Nadu, India.(Email: shubham193sahu@ gmail.com)

Dr. K. Saravanan, Associate Professor, Department of Electrical and Electronics Engineering, SRM Institute of Science and Technology, Chennai, Tamil Nadu, India.(Email: saravanank96@gmail.com) least two sustainable sources alongside a capacity framework could tackle the issue.

Normally wind and sun powered vitality sources are utilized to supplement each other due the idea of both of them present at once, for example without daylight, especially high measure of wind is experienced. Anyway in this venture, aside from a sun powered PV board, a battery is utilized as the assistant source to control the circuit. The nearness of a helper source is to guarantee that the other source makes up for the deficiencies of the principal source and satisfies the heap request. To make this mix conceivable, the nearness of intensity electronic converters is principal to check the framework dependability and to enhance the effectiveness of intensity exchange.

Potential arrangements of the half and half framework are primarily AC shunt coupling, DC shunt coupled and crossover coupled frameworks. Notwithstanding high proficiency and minimal effort, to guarantee greatest power point following (MPPT), a DC-DC converter is required to give input/yield voltage change proportion and an extensive scope of brisk voltage and current control[6]. The aftereffect of the consequences of two sources in the framework is the utilization of autonomous electrical electronic converters, which scrambles a few segments of converters, therefore decreasing $25 \%$ of these semiconductors switches.

A few DC-DC converters are viewed as coordinated close by different sustainable power sources. High recurrence current sounds is infused into the framework in light of half breed sustainable power source framework [2]. Because of this, few warming issues are experienced consequently diminishing productivity and life span, which isn't feasible for an ordinary DC-DC converter to wipe out. Thus an uninvolved information channel is included independently for the reason of wiping out the consonant substance, accordingly making the framework massive and costly.

This paper proposes another converter topology for an incorporated Cuk-SEPIC for coordinating an energy component (battery) and a PV framework. The need of taking out info channels to lessen high recurrence music is one of the upsides of the proposed converter [7]. Excepting these, it is required to work in both concurrent and singular modes. While the Cuk converter manages the PV framework with P\&O (Perturb and Observe) MPPT (Maximum Power Point Tracking) strategy, the SEPIC is utilized to control the battery that goes about as the assistant source. The significant 


\section{A NEW HYBRID CONVERTER DESIGN USING COMBINED SEPIC-CUK CONVERTERS}

preferred standpoint of the framework is that without sufficient daylight, for example at the point when the PV framework is unfit to control the whole circuit, the battery ventures in and fulfils the heap request [8]. Consequently the aggregate of the yield voltages of the sources gives the normal yield voltage of the framework, because of the sources' elective nature.

\section{ABOUT CUK CONVERTER AND SEPIC}

A Cuk Converter is a DC-DC converter that has a yield voltage, whose extent is either more prominent than or lesser than the size of information voltage. Regardless of whether coupling of vitality is accomplished in it by having a buck converter close by a capacitor, it basically is a lift converter.

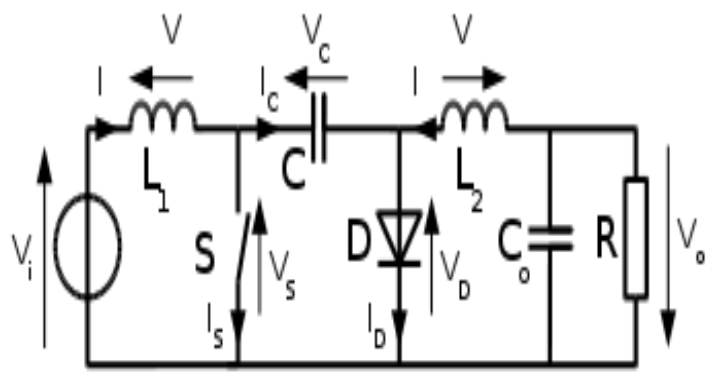

Fig. 2.1 Cuk Converter Circuit

A Cuk converter circuit generally includes capacitors, inductors, a transistor and a diode. Its schematic can be observed in Fig. 2.1. Since, it's miles a rearranging converter, the voltage yielded is of the opposite polarity as compared to the voltage at the input. The capacitor $\mathrm{C}$ is applied to change energy and is related alternatively to the data and to the converter's output by means of the transistor's and the diode's over compensation.

The two inductors $L_{1}$ and $L_{2}$ are instrumental in converting the sources of voltage, placed at the output $\left(C_{o}\right)$ and the input $\left(V_{i}\right)$, into sources of current. For a minute scale of time, an inductor can be assumed to be a source of current due to it maintaining current constantly. Once the source of voltage is directly connected to the capacitor, parasitic resistance plays a role in limiting the current [9]. This is why the conversion is inevitable. Using a source of current to charge a capacitor negates the energy loss as stipulated.

Similarly like the various unique converters, Cuk converter can generally operate in either of intermittent continuous mode or nonstop mode. In complete fair assessment, the varied nature of this converter makes it able to operate in abnormal voltage mode as well.

A SEPIC (Single-ended primary inductor converter) is also a DC-DC converter, like the Cuk converter, that has its yield voltage either more distinguished than, lesser than or equivalent to its initial voltage magnitude. Fundamentally it may mission up and venture down the voltage.

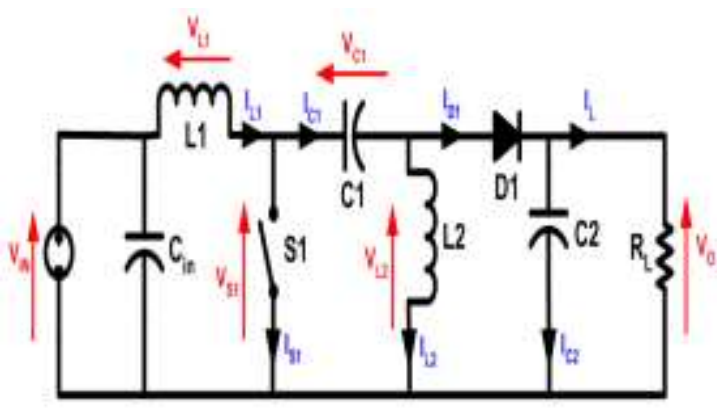

Fig. 2.2 SEPIC Circuit

In the persistent mode for SEPIC, current through inductor $L_{1}$ never approaches 0 . While in consistent state, input voltage is equivalent to average voltage crosswise over capacitor $C_{1}$. Presently, the normal current through it is 0 as it obstructs the DC current. This makes $L_{1}$ the main hotspot for DC load current. This normal burden current is equivalent to average current through inductor $L_{2}$. After careful observation at the normal voltages, the subsequent information can be inferred:

$$
V_{i n}=V_{C_{1}}+V_{L_{1}}+V_{L_{2}}
$$

As the nominal voltage of $V_{C_{1}}$ is sameas $V_{i n}, V_{L_{1}}=-V_{L_{2}}$. Thus, the 2 inductors may be combined together as a comparable centre. As the voltages are the equivalent in magnitude, their property of the mutual inductance will be equivalent to zero. Likewise, because the voltages are the equivalent in magnitude, the current flowing from the two inductors could be equal in value. The normal current flows can be summed as pursues (regular capacitor flows have to be zero):

$$
I_{D_{1}}=I_{L_{1}}-I_{L_{2}}
$$

While the S1 switch is switched on, the current $I_{L_{1}}$ is incremented and the inductor current $I_{L_{2}}$ is decremented step by step $[1,2]$. The vitality to obtain the current $I_{L_{1}}$ is gotten from the source of voltage. Since $S_{1}$ is switched quickly and the voltage $V_{L_{1}}$ is equal to $V_{i n}$, the voltage $V_{L_{2}}$ is greater or lesser than $-V_{C_{2}}$. Thus, the capacitor $C_{1}$ enhances the power to expand the dimensions of the current $I_{L_{2}}$ and alongside these traces increment the current put away in $L_{2}$. The simplest technique to ascertain this is to reflect on consideration on the inclination voltages of the circuit in a D.C. converter, at that point close $S_{1}$.

While switch $\mathrm{S} 1$ is switched OFF, the modern $I_{C_{1}}$ turns into equal to the current $I_{L_{1}}$, considering that inductors don't permit activate adjustments in cutting-edge. The cutting-edge $I_{L_{2}}$ will keep on streaming the terrible manner, in truth it by no means inverts bearing. It thoroughly may be visible that a poor $I_{L_{2}}$ will upload to the modern $I_{L_{1}}$ to make bigger the modern-day conveyed to the heap. Utilizing Kirchhoff's Current Law, it very well may be confirmed that $I_{D_{1}}=I_{C_{1}}$ $I_{L_{2}}$. It might then be capable of be gotten, that at the same time as $\mathrm{S} 1$ is off, control is conveyed to the heap from both $L_{2}$ and $L_{1}$. As similar as it seems, $C_{1}$ is being charged by using $L_{1}$ on this off cycle, and will thusly revive $L_{2}$ amid the on cycle. 
As the potential (voltage) crosswise over capacitor $C_{1}$ may additionally turn round route each cycle, a non-enraptured capacitor should be utilized. In any case, a spellbound tantalum or electrolytic capacitor might be applied in a few cases, when you consider that the capability (voltage) crosswise over capacitor $C_{1}$ might not exchange besides if the transfer is shut sufficiently long for a half cycle of reverberation with inductor $L_{2}$, and at this factor the modern-day in inductor $L_{1}$ may be very large.

The capacitor $C_{i n}$ proceeds to negate the effects of the parasitic properties of inductance and intrinsic obstruction of the energy to be delivered. The friendly capabilities of the SEPIC are workable in the presence of capacitor $C_{1}$ and the inductor $L_{2}$. Inductor $L_{1}$ and the switch $S_{1}$ form up to be a desirableboost converter, thatgenerates a voltage $\left(V_{S_{1}}\right)$, which is greater in magnitudeas compared to $V_{i n}$, whose value is decided by way of the duty cycle of the switch S1. As the generalcrossover voltage in $C_{1}$ is $V_{i n}$, the yielded voltage $\left(V_{o}\right)$ is $V_{S_{1}}-V_{i n}$. In case $V_{S_{1}}$ is not exactly twice of $V_{i n}$, at that point the yielded voltage might be no longer equal to the input voltage. On the off chance that $V_{S_{1}}$ is morethan two timesof $V_{i n}$, at that factor the yielded voltage can be morethan the input voltage.

Fig. 3.1 Proposed hybrid converter circuit

The proposed circuit as appeared in Fig. 3.1 is a converter topology which transforms from DC to DC, that utilizes a solitary hub of exchanging which will be basic to both the Cuk and SEPIC stages to give positive and negative yields that are ground-referenced.

At the point when the switch is 'ON', every one of the inductors begin charging while the capacitors begin releasing. At the point while the switch turns 'OFF', inductor current flows are diverted onto the two diodes. Additionally, the capacitors begin charging while the inductors releases current[10].

While working in constant conduction mode, the switch turns 'ON' again preceding the total release of any inductor. The half and half converter can give expansive advance down, just as venture up voltage transformation proportions. The converter has a yield/input proportion of $\mathrm{D} /(1-\mathrm{D})$ [1] for every one of the positive and negative DC yield terminals, giving advance up change to obligation proportions more prominent than $1 / 2$, and working in venture down mode for

\section{PROPOSED CIRCUIT AND ITS OPERATION}

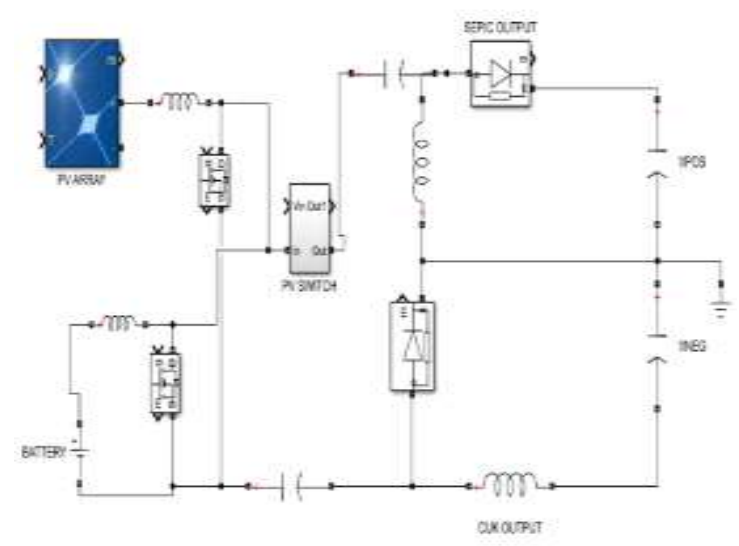

obligation proportions beneath $1 / 2$. The converter's general increase (for example considering the voltage output as the gross sum of the positive and negative spectrums of the terminal voltages) is 2D/ (1-D) This particular voltage proportion permits guideline of bigger info voltage varieties with a similar obligation cycle extend, or on the other hand enables the converter to deal with a similar information voltage variety with a smaller obligation cycle run, taking into account littler inductors to be utilized.

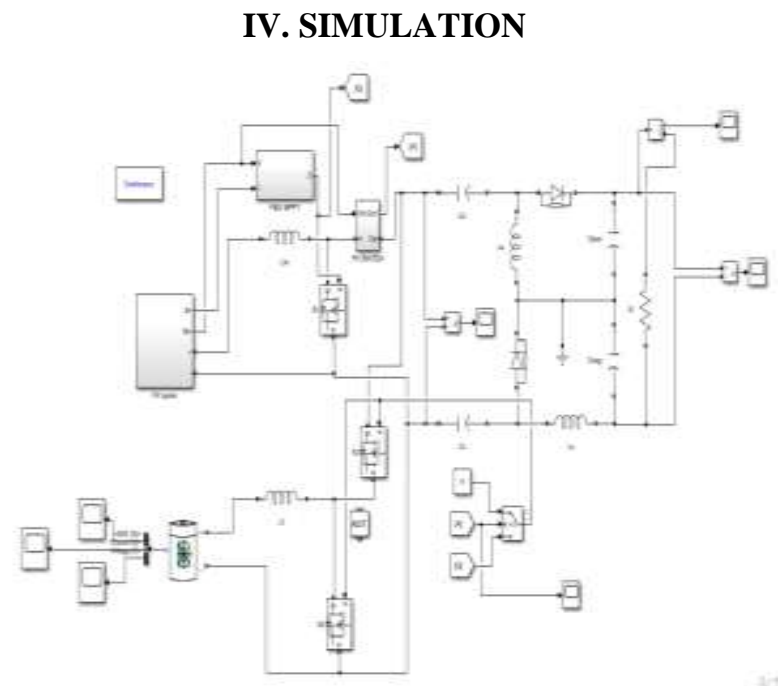

Fig. 4.1 The simulation diagram of the proposed converter

The circuit appeared in Fig 4.1 showcases the circuit utilized for the re-enactment of the proposed converter demonstrate. A PV board is chosen as the fundamental source, which is then associated with the MPPT controller. The Perturb and Observe (P\&O) technique for MPPT is utilized in this recreation. The assistant wellspring of the proposed model is a battery. In the event that, the PV is unfit to give adequate power, the battery is entrusted with driving the circuit.

The PV setup is the associated with the PV switch which handles the exchanging task when PV is unfit to give the power completely [3]. This exchanging task happens pretty unexpectedly. At the point when MOSFET S2 is ON, the battery is going about as the source and driving the circuit. At the point when MOSFET S3 is ON, MOSFET S1 is ON too, subsequently PV goes about as the source while the battery is being charged.

The crossover converter setup is included SEPIC and Cuk converters. The Top portion of the proposed model has a place with the SEPIC part while the base portion of the model [5] has a place with the Cuk part. Aside from this, the SEPIC some portion of the converter is constrained by the PV and the Cuk some portion of the converter is constrained by the battery.

At the point when $\mathrm{PV}$ is $\mathrm{ON}$, it drives the Cuk part of the circuit and the voltage got is higher than the information, in this manner showing help activity of the converter. Comparable yield is watched for the SEPIC part, when battery is dynamic. 


\section{A NEW HYBRID CONVERTER DESIGN USING COMBINED SEPIC-CUK CONVERTERS}

By deliberately setting extensions over the circuit, we can realize the minutest insights about the yield of the converter. The yield voltage, current qualities are shown. Aside from these, we know the info voltage to the converter and furthermore the battery qualities are gotten.

V. Design Specifications and related formulae

$$
\begin{aligned}
& L_{\text {in }} \text { min }=\frac{V_{\text {in }}^{2} V_{\text {out }} T_{S}}{\left(V_{\text {in }}+V_{\text {out }}\right) P_{\text {out }}\left(\Delta_{L_{\text {in }} i_{\text {max }}} \%\right)}
\end{aligned}
$$

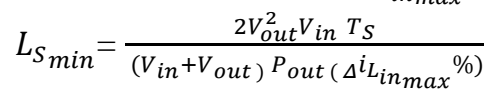

$$
\begin{aligned}
& L_{C_{\text {min }}}=\frac{2 V_{\text {out }}^{2} V_{\text {in }} T_{S}}{\left(V_{\text {in }}+V_{\text {out }}\right) P_{\text {out }}\left(\Delta \Delta_{L_{\text {in }}} \%\right)} \\
& C_{P O S_{\text {min }}}=\frac{P_{\text {out }} T_{S}}{2\left(V_{\text {in }}+V_{\text {out }}\right) V_{\text {out }}\left(\Delta^{v} C_{\text {PoS max }} \%\right)} \\
& C_{N E G_{\min }}=\frac{P_{\text {out }} T_{S}\left({ }^{i_{L_{C}}} \max _{\text {max }} \%\right)}{16 V_{\text {out }}^{2}\left(\Delta^{v} C_{N E G_{\max }} \%\right)} \\
& C_{S_{\text {min }}}=\frac{V_{\text {in }}^{2} V_{\text {out }} T_{S}}{V_{\text {in }}\left(V_{\text {in }}+V_{\text {out }}\right) P_{\text {out }} \Delta i_{L_{\text {in }} \text { max }} \%} \\
& C_{C_{\text {min }}}=\frac{V_{\text {in }}^{2} V_{\text {out }} T_{S}}{2\left(V_{\text {in }}+V_{\text {out }}\right)^{\wedge} 2 P_{\text {out }} \Delta i_{L_{\text {in }} \text { max }} \%}
\end{aligned}
$$

The various formulae used to design the proposed hybrid converter are present above where,

$L_{i n_{\text {min }}}$ Is the minimum value of input inductor, $V_{i n}$ is the input voltage, $V_{\text {out }}$ is the output voltage, $P_{\text {out }}$ is the output power, $T_{S}$ and is the switching period, $L_{S}$ is the inductor in the SEPIC part, $C_{S}$ is the capacitor in the SEPIC part [4], $L_{C}$ is the inductor in the Cuk part, $C_{C}$ is the capacitor in the Cuk part, $C_{P O S}$ is the capacitor at the positive end output of the circuit (the SEPIC side), $C_{N E G}$ is the capacitor at the negative end output of the circuit (the Cuk side).

\section{A. Simulation Component Details}

The component values for the circuit diagram as shown in the simulation are as follows:-

$$
\begin{aligned}
& C_{S}=1.5 \mu \mathrm{F} \\
& C_{C}=0.47 \mu \mathrm{F} \\
& C_{P O S}=5 \mu \mathrm{F} \\
& C_{N E G}=0.33 \mu \mathrm{F} \\
& L_{I N}=545 \mu \mathrm{H} \\
& L_{S}=891 \mu \mathrm{H} \\
& L_{C}=891 \mu \mathrm{H}
\end{aligned}
$$

\section{B. Hardware Component Details}

The component values for the circuit used in the hardware model are as follows:-

$C_{S}=470 \mu \mathrm{F} ; 50 \mathrm{~V} ; 85^{\circ} \mathrm{C}$

$C_{C}=470 \mu \mathrm{F} ; 50 \mathrm{~V} ; 85^{\circ} \mathrm{C}$

$C_{P O S}=470 \mu \mathrm{F} ; 50 \mathrm{~V} ; 85^{\circ} \mathrm{C}$

$C_{N E G}=470 \mu \mathrm{F} ; 50 \mathrm{~V} ; 85^{\circ} \mathrm{C}$

$L_{I N}=545 \mu \mathrm{H}$

$L_{S}=891 \mu \mathrm{H}$

$L_{C}=891 \mu \mathrm{H}$

- Other Hardware Components

Output Load (LED): $-2.5 \mathrm{~V}$

Driver Circuit IC: - TLP250

Diodes: - IN4007

2-channel: $-12 \mathrm{~V}$ relay board

Arduino Uno

Transformer: - 230/12V

\section{RESULTS AND CONCLUSIONS}

A. Simulation Results

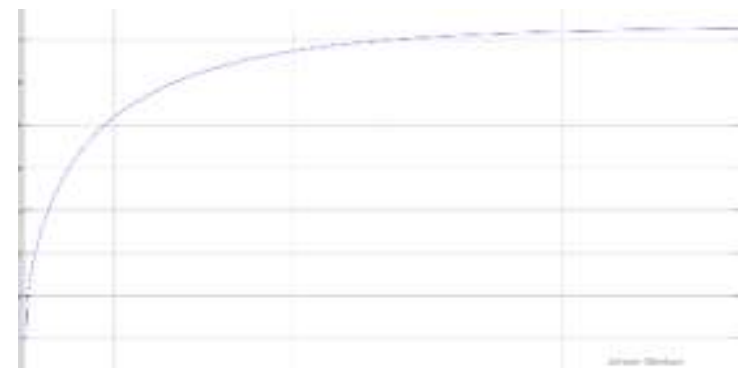

Fig. 6.1 Voltage v/s time when $P V$ is active

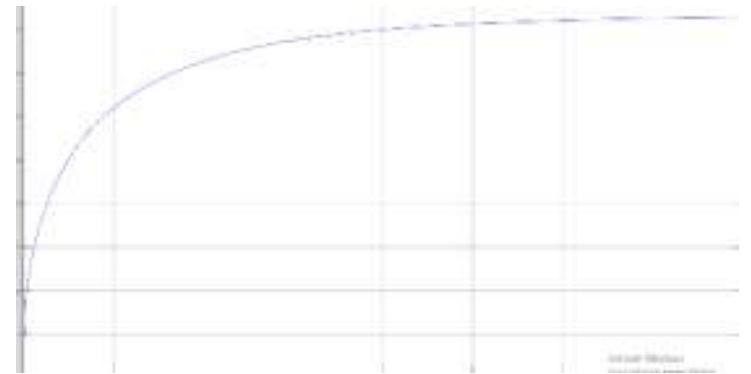

Fig. 6.2 Current v/s time when $P V$ is active

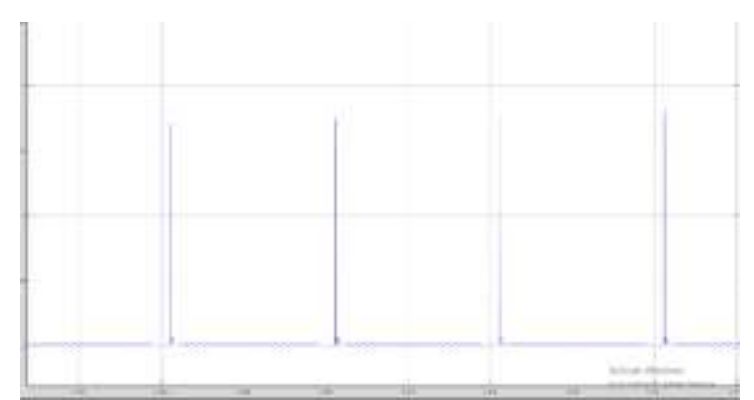

Fig. 6.3 Input level characteristics when $P V$ is active

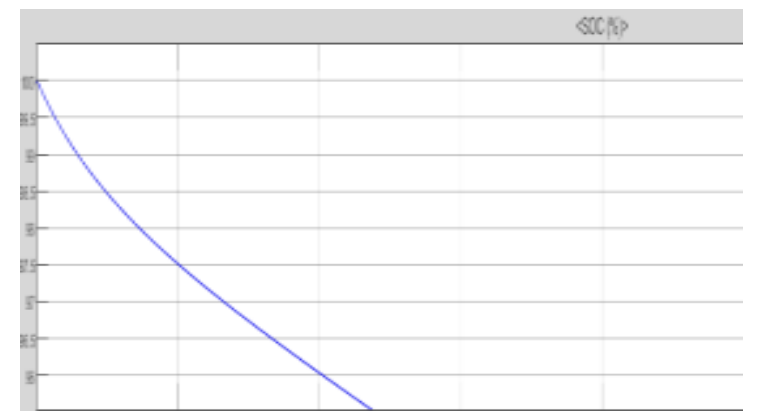

Fig. 6.4 State of Current (SOC) of battery when PV is active

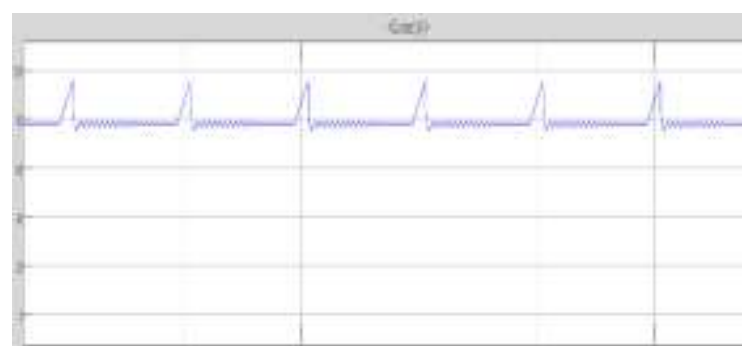

Fig. 6.5 Current of the battery when PV is active 


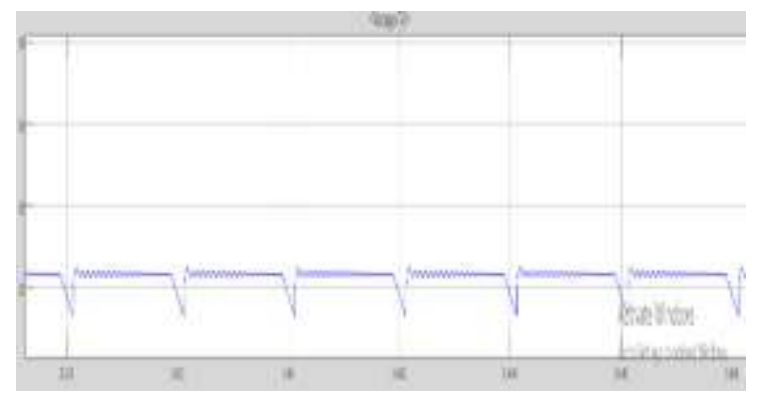

Fig. 6.6 Voltage of the battery when PV is active

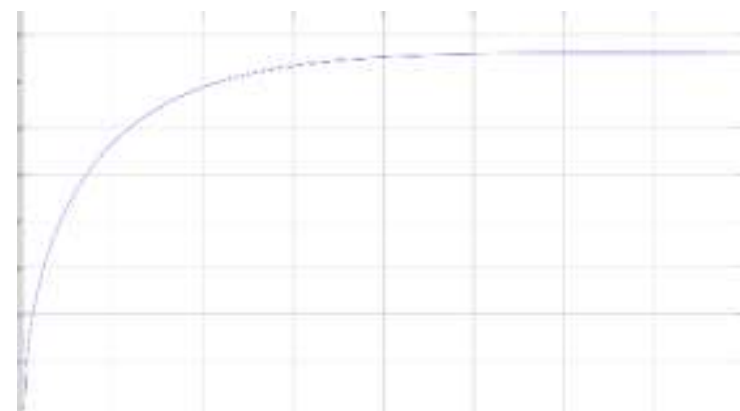

Fig. 6.7 Current v/s time when battery is active

Fig. 6.8 Voltage v/s time when battery is active

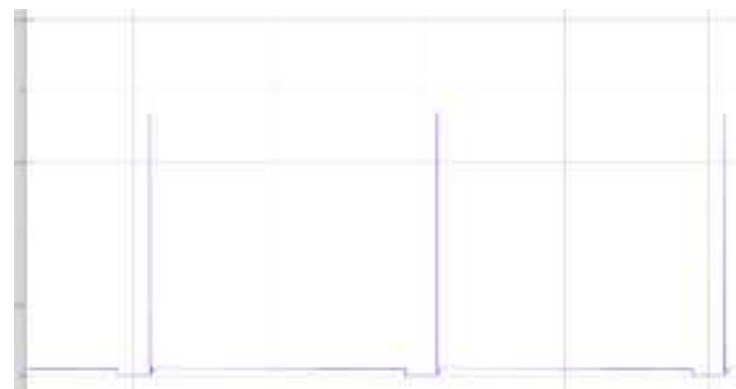

Fig. 6.9 Input level characteristics when battery is active

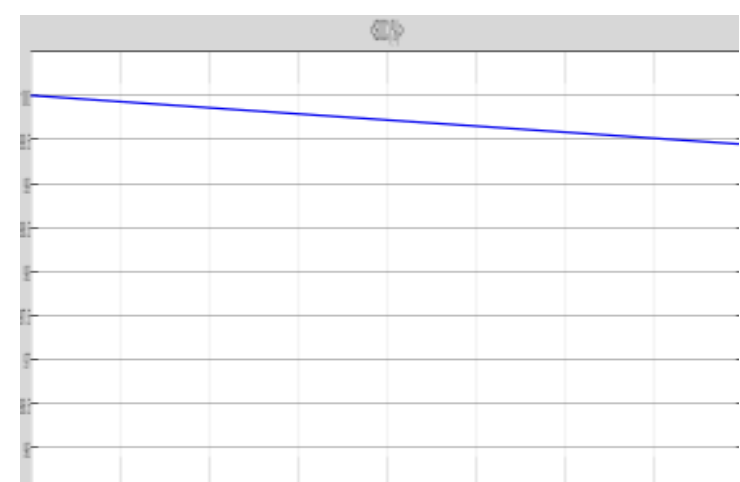

Fig. 6.10 State of Current (SOC) of battery when battery is active

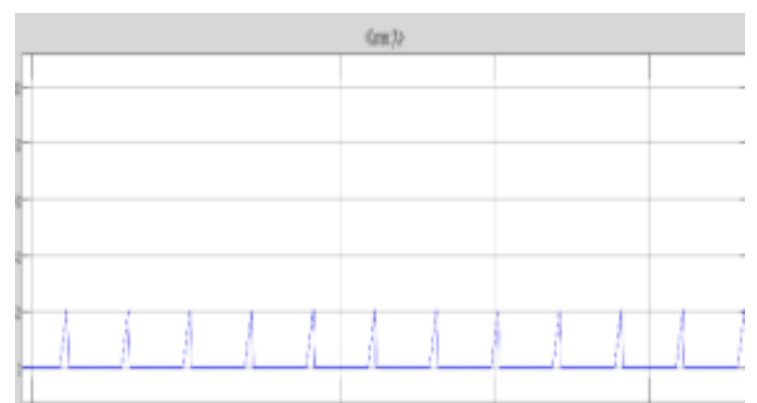

Fig. 6.11 Current of the battery when battery is active

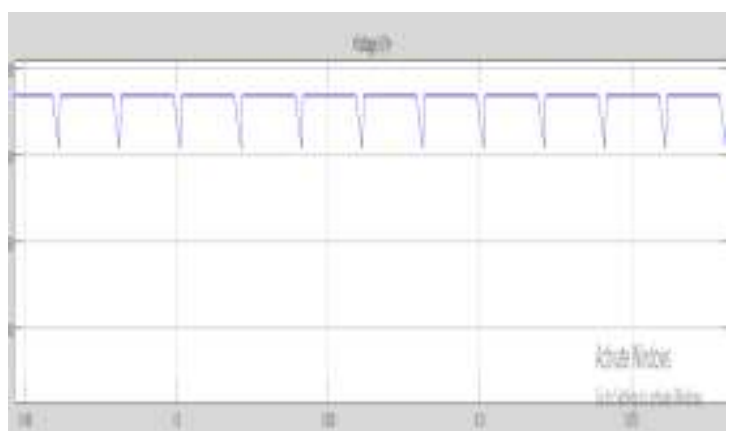

Fig. 6.12 Voltage of the battery when battery is active

\section{B. Hardware Results}

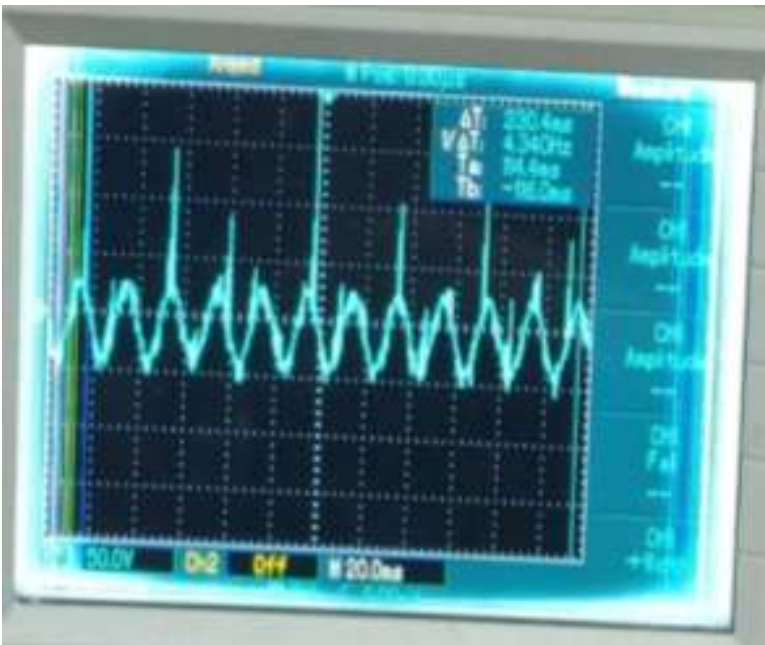

Fig 6.13 Hardware Output When PV is active

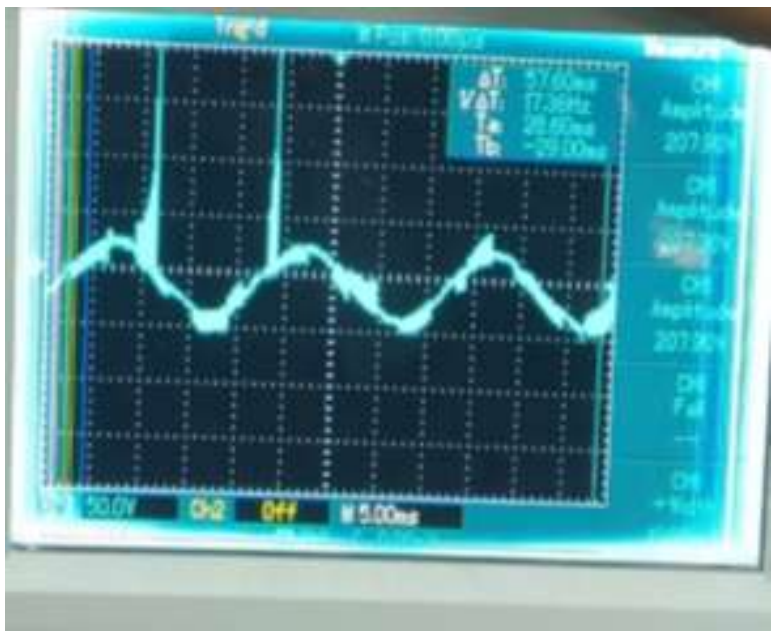

Fig 6.14 Hardware Output When Battery is active

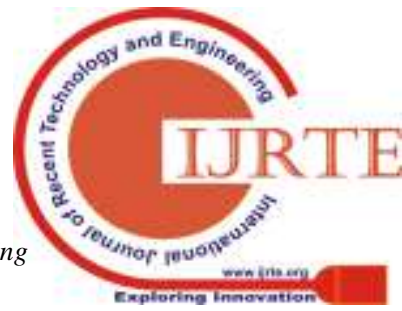




\section{REFERENCES}

1. Kumaran Nathan, Saikat Ghosh, Yam Siwakoti, Teng Long, "A New DC-DC Converter for Photovoltaic Systems: Coupled-Inductors Combined Cuk-SEPIC Converter, IEEE Transactions on Energy Conversions, October 2018.

2. W. Xiao, N. Ozog, and W. G. Dunford, "Topology study of photovoltaic interface for maximum power point tracking," IEEE Transactions on Industrial Electronics, vol. 54, no. 3, pp. 1696-1704, June 2007.

3. G. R. Walker and P. C. Sernia, "Cascaded dc-dc converter connection of photovoltaic modules," IEEE Transactions on Power Electronics, vol. 19, no. 4, pp. 1130-1139, July 2004.

4. D. Meneses, F. Blaabjerg, Garcia, and J. A. Cobos, "Review and comparison of step-up transformer less topologies for photovoltaic ac module application," IEEE Transactions on Power Electronics, vol. 28, no. 6, pp. 2649-2663, June 2013.

5. M. Forouzesh, Y. P. Siwakoti, S. A. Gorji, F. Blaabjerg, and B. Lehman,"Step-up dc-dc converters: A comprehensive review of voltage-boostingtechniques, topologies, and applications," IEEE Transactions on Power Electronics, vol. 32, no. 12, pp. 9143-9178, Dec 2017.

6. M. Forouzesh, Y. Shen, K.Yari, Y. P. Siwakoti, and F. Blaabjerg, "Highefficiency high step-up dc-dc converter with dual coupled inductorsfor grid-connected photovoltaic systems," IEEE Transactions on PowerElectronics, vol. 33, no. 7, pp. 5967-5982, July 2018.

7. S. V. Araujo, P. Zacharias, and R. Mallwitz, "Highly efficient singlephasetransformerless inverters for grid-connected photovoltaic systems,"IEEE Transactions on Industrial Electronics, vol. 57, no. 9, pp. 3118-3128, Sept 2010

8. J. M. Shen, H. L. Jou, and J. C. Wu, "Novel transformerless gridconnectedpower converter with negative grounding for photovoltaicgeneration system," IEEE Transactions on Power Electronics, vol. 27,no. 4, pp. 1818-1829, April 2012.

9. Y. P. Siwakoti and F. Blaabjerg, "Common-ground-type transformerlessinverters for single-phase solar photovoltaic systems," IEEE Transactionson Industrial Electronics, vol. 65, no. 3, pp. 2100-2111, March2018.

10. H. Xiao and S. Xie, "Leakage current analytical model and application insingle-phase transformerless photovoltaic grid-connected inverter," IEEETransactions on Electromagnetic Compatibility, vol. 52, no. 4, pp. 902-913, Nov 2010. 